\title{
First Report of Agrobacterium tumefaciens mediated genetic transformation of aquatic Rice paddy herb (Limnophila aromatica)
}

\author{
Allah Bakhsh ${ }^{1 *}$, Muhammad Aasim ${ }^{3}$, Abu Bakir Zia ${ }^{1}$, Muhammet Doğan ${ }^{2}$, \\ Gökhan Sadı², Mehmet Karataş ${ }^{3}$, Khalid Mahmood Khawar ${ }^{4}$ \\ ${ }^{1}$ Department of Agricultural Genetic Engineering, Faculty of Agricultural Sciences and Technology, Niğde University, 51240 Niğde, Turkey \\ ${ }^{2}$ Department of Biology, Kamil Özdağ Faculty of Sciences, Karamanoğlu Mehmetbey University, 70200 Karaman, Turkey \\ ${ }^{3}$ Department of Biotechnology, Faculty of Science, Necmettin Erbakan Universityy, 42060 Konya, Turkey \\ ${ }^{4}$ Department of Field Crops, Faculty of Agriculture, Ankara University, 0611 Dişkapı/Ankara, Turkey.

\section{A R T I C L E I N F O}

\section{Article history:}

Received 21 April 2016

Accepted 09 June 2016

Available online, ISSN: $2148-127 \mathrm{X}$

Keywords:

Agrobacterium

Genetic transformation

Shoot tip

GUS

nptII

${ }^{*}$ Corresponding Author:

E-mail: abthebest@gmail.com \begin{abstract}
A B S T R A C T
The study presents first report of Agrobacterium mediated genetic transformation in Rice paddy herb (Linmophila aromatica). A. tumefaciens strain $\mathrm{C} 58 \mathrm{C} 1$ harboring pBin19 Plasmid containing $\beta$-glucuronidase (GUS) and neomycin phosphotransferase II (nptII) gene, under the control of $35 \mathrm{~S}$ promoter and NOS terminator was used. Shoot tip explants were inoculated for $30 \mathrm{~min}$ followed by co-cultivation for $72 \mathrm{~h}$ and selected on agar semi solidified MS medium containing $100 \mathrm{mg} / \mathrm{l} \mathrm{Kanamycin} \mathrm{and} 1.0 \mathrm{mg} / \mathrm{l} \mathrm{BA}$; whereas total number of 78 putative transgenic shoots were obtained. The shoots were rooted on MS medium containing $1.0 \mathrm{mg} / \mathrm{l} \mathrm{IBA}$ and $100 \mathrm{mg} / \mathrm{l} \mathrm{Kanamycin} \mathrm{where} 43$ plants survived and rooted. Expression of GUS gene in the putative transgenics was confirmed by histochemical GUS assay. Visible localised gus expression was noted in a few cells and callus tissues of 4 plantlets that were photographed using compound light microscope.
\end{abstract}

\section{Introduction}

Aquatic plants have great importance in remediation of water ecosystem. They have ability to increase or decrease the efficiency of an ecosystem based on their position as primary and secondary producers (Chi et al., 1998). Aquatic plants are the primary source of oxygen in water bodies (Gorai et al., 2014), source of feed, shelter and providing excellent environment for the safety of fish, their egg laying and hatching (Brahmachari, 2008). Most of the aquatic plants/weeds are also used for ornamental purpose in aquariums all over the world owing to their attractive green, pink and red colours. Many recent studies report use of aquatic plants for phytoremediation of municipal wastes (Kukongviriyapan et al., 2003; Bui et al., 2004) and as pollution biomonitors of land locked water bodies around the world (Sribusarakum et al., 2004).

Rice paddy herb (Linmophila aromatica), family Scrophulariaceae is an important perennial ornamental and medicinal aquatic or semi-aquatic plant of tropical origin. People in South East Asian countries cultivate Limnophila (Gorai et al., 2014) as spice and medicinal herb (Chi et al., 1998). It contains important flavonoids (Bui et al., 2004) that also exert antioxidant activities (Kukongviriyapan et al., 2003; Sribusarakum et al., 2004). The leaves of Limnophila contain $0.1 \%$ essential oil (Brahmachari, 2008) with limonene, perillaldehyde and ketone, cis-4caranone and others as main constituents (Katzer, 2014). Moreover, it is also commonly used to treat dysentery, elephantiasis, indigestion and menstrual problems (Bhuiyan et al., 2010).

Advancement in genetic engineering and biotechnology have enabled the scientists to engineer crops with desired traits. Agrobacterium mediated genetic transformation studies in aquatic plants started late and first report on genetic transformation was reported in Lemna gibba and Lemna minor in 2001 (Yamamoto et al., 2001). To date, a number of optimization of Agrobacterium mediated genetic transformation studies in aquatic plants has been reported including Ipomea aquatica (Khamwanı et al., 2003; Meerak et al., 2006), Typha latifolia (Nandakumar et al., 2005), Cryptocoryne willisii (Wong et al., 2013), L. minor (Chhabra et al., 2011), Mentha aquatica (Hajian et al., 2011) and Bacopa monnieri (Nisha et al., 2004; Ramesh et al., 2011; Mahender et al., 2012; Yadav et al., 2014; Kumari et al., 2015).

To date no effort has been made for optimization of genetic transformation studies in L. aromatica. The present study is the first report on the Agrobacterium mediated gentic transformation studies on L. aromatica with aim to develop protocol for future aquatic plant biotechnlogy studies. 


\section{Material and Methods}

The plants were taken from Karamanoglu Mehmetbey University, Department of Biology, Biotechnology Laboratory and multiplied following Karataş and Aasim (2015) to obtain sufficient plant material (explants) for genetic transformation studies. The shoot tip explants were cultured on MS (Murashige and Skoog 1962) medium containing $1.0 \mathrm{mg} / \mathrm{l} \mathrm{BA}$ for 6 weeks under $16 \mathrm{~h}$ light photoperiod using White LEDs at $23^{\circ} \mathrm{C}$. All mediums used in this study were prepared by adding 30 $\mathrm{g} / \mathrm{L}(\mathrm{w} / \mathrm{v})$ sucrose and $0.65 \%(\mathrm{w} / \mathrm{v})$ agar to distilled water and $\mathrm{pH}$ was adjusted to 5.8. Therafter, media were autoclaved at $104 \mathrm{kPa}$ atmospheric pressure and $120^{\circ} \mathrm{C}$ for $21 \mathrm{~min}$.

This study used A. tumefaciens strain C58C1 harboring pBin 19 containing $\beta$-glucuronidase (GUS) and neomycin phosphotransferase II (nptII) gene, driven by $35 \mathrm{~S}$ promoter and nos terminator (Figure-1). GUS gene was interrupted by an intronic region to induce expression of GUS only from eukaryotic genes. A single colony of Agrobacterium was inoculated in nutrient broth (NB) containing $50 \mathrm{mg} / \mathrm{l}$ kanamycin and rifampicin each followed by overnight incubation at $28^{\circ} \mathrm{C}$. Thereafter, the bacterial suspension was diluted with liquid MS medium to optimum optical density $\left(\mathrm{OD}_{600}\right)$ to $0.6-0.8$. Shoot tip explants were isolated and inoculated for $30 \mathrm{~min}$. It was followed by co-cultivation for $72 \mathrm{~h}$ on MS medium containing $1.0 \mathrm{mg} / \mathrm{l} \mathrm{BA}$. Thereafter, the explants were shifted to selection medium supplemted with $100 \mathrm{mg} / \mathrm{l}$ Kanamycin, $500 \mathrm{mg} / \mathrm{l}$ broad spectrum antibiotic (Duocid) and $1.0 \mathrm{mg} / \mathrm{l} \mathrm{BA}$. Duocid was used to suppress growth of Agrobacterium. After 6 weeks of culture, in vitro regenerated kanamycin resistant plants were excised and aseptically transferred to rooting medium containing 1.0 $\mathrm{mg} / \mathrm{l} \mathrm{IBA}$ and $100 \mathrm{mg} / \mathrm{l}$ Kanamycin.

Leaf samples were taken from in vitro regenerated plantlets and subjected to GUS analysis (Jefferson et al., 1987). All samples were dipped in X-GLUC solution (100 $\mathrm{mM}$ sodium phosphate ( $\mathrm{pH} 7.0), 10 \mathrm{mM}$ EDTA, $0.1 \%$ Triton X-100, and $1 \mathrm{mM}$ 5-bromo-4-chloro-3-indolyl glucuronide (X-Gluc) and incubated at $37^{\circ} \mathrm{C}$ for $1-2 \mathrm{~h}$. The solution was decanted and the tissues were dipped in ethanol for $24 \mathrm{~h}$ to destroy chlorophyl and visualise GUS positive cells/tissues. Similar procedure was also employed for 2-4 weeks old callus of Limnophila to identify the genetically transformed tissues. All samples were also checked under compund light microscope for confirmation of GUS expression cells.

$$
35 \mathrm{~S}>\sqrt{\text { uidA }}>\sqrt{\mathrm{NO}}>\sqrt{35 \mathrm{~S}} \sqrt{\text { nptII }}
$$

Figure 1 Schematic diagram of T-DNA region with uid and nptII genes with $35 \mathrm{~S}$ promotor and NOS terminator. Kanamycin was used at concentration of $100 \mathrm{mg} / \mathrm{l}$ as plant selectable marker.

\section{Results and Discussion}

Agrobacterium strains and explants types play an important role in the transformation process, as they are responsible both for infectivity but also for the efficiency of gene transfer. The suitability of $\mathrm{C} 58 \mathrm{C} 1$ strain harbouring various plasmids for the transformation of many economic plants has already been reported (Bakhsh et al. 2014). This study used shoot tip explants taken from in vitro grown stock material multiplied on MS medium containing $1.0 \mathrm{mg} / \mathrm{l} \mathrm{BA}$ for 6 weeks following Karataş and Aasim (2015). All explants proliferated and multiple shoot induction after 6 weeks of culture. Thereafter, in vitro regenerated shoot tip explants were taken for genetic transformation studies. Shoot tip explants are potent explants used for genetic transformation studies in other economically important plants like corn (Cao et al., 2014; Zhong and Sticklen, 2000), cotton (Gould et al., 1998; Lei et al., 2012), soybean (Loganathan et al., 2010), jute (Saha et al., 2014), eucalyptus (Silva et al., 2011) etc. showing their suitability for genotype independent genetic transformation.

The explants were inoculated for $30 \mathrm{~min}$ to achieve genetic transformation from shoot tip explants. Longer exposure of explants in the incoulation medium tended to excessive Agrobacterium growth in the co-cultivation medium. After inoculation, shoot tip explants were shifted to co-cultivation medium for $72 \mathrm{~h}$ followed by transfer to selection medium for 6 weeks using Kanamycin as selection agent. Shoot prolifeartion with callus induction started within two weeks with clear multiple shoots (Figure 2a) was recorded after 4 weeks of culture. A total of 78 putative transgenic shoots were produced on kanamycin containing selection medium. These shoots were shifted to rooting medium containing $100 \mathrm{mg} / \mathrm{l}$ Kanamycin resulting in selection of 43 putative transgenic plantlets that were subjected to histochemical GUS analysis for staining. 43 out of 78 plants (55.13\%) plants showing regeneration on MS medium supplemented with Kanamycin were speculated a escapes that were further confirmed by GUS histochemical analysis. Although Kanamycin is believed to be a good selection agent for putative plants, still escapes have been documented in various genetic transformation studies (Bakhsh et al., 2014; McCormick et al., 1986).

GUS histochemical assays revealed blue staining of leaf samples under light microscope (Figure 2a). A total of 4 samples (plants) showed GUS expression out of selected 43 plants. A GUS activity revealed a heterogeneous pattern of staining with the substrate 5bromo-4-chloro-3-indoyl- $\beta$-d-glucuronic acid in some transformed cell cultures. Blue-staining was often observed on few cells among unstained callus masses. Results clearly revealed low genetic transformation efficiency for GUS gene with low and localised expression. In order to find out the reasons for low GUS expression, a new experiment was performed and 2-4 weeks old explants (with shoot buds or calli) subjected to GUS analysis. Explants (calli with shoot buds) showed localised GUS expression with blue staining at specific sites under microscope (Figure 2c, d). 

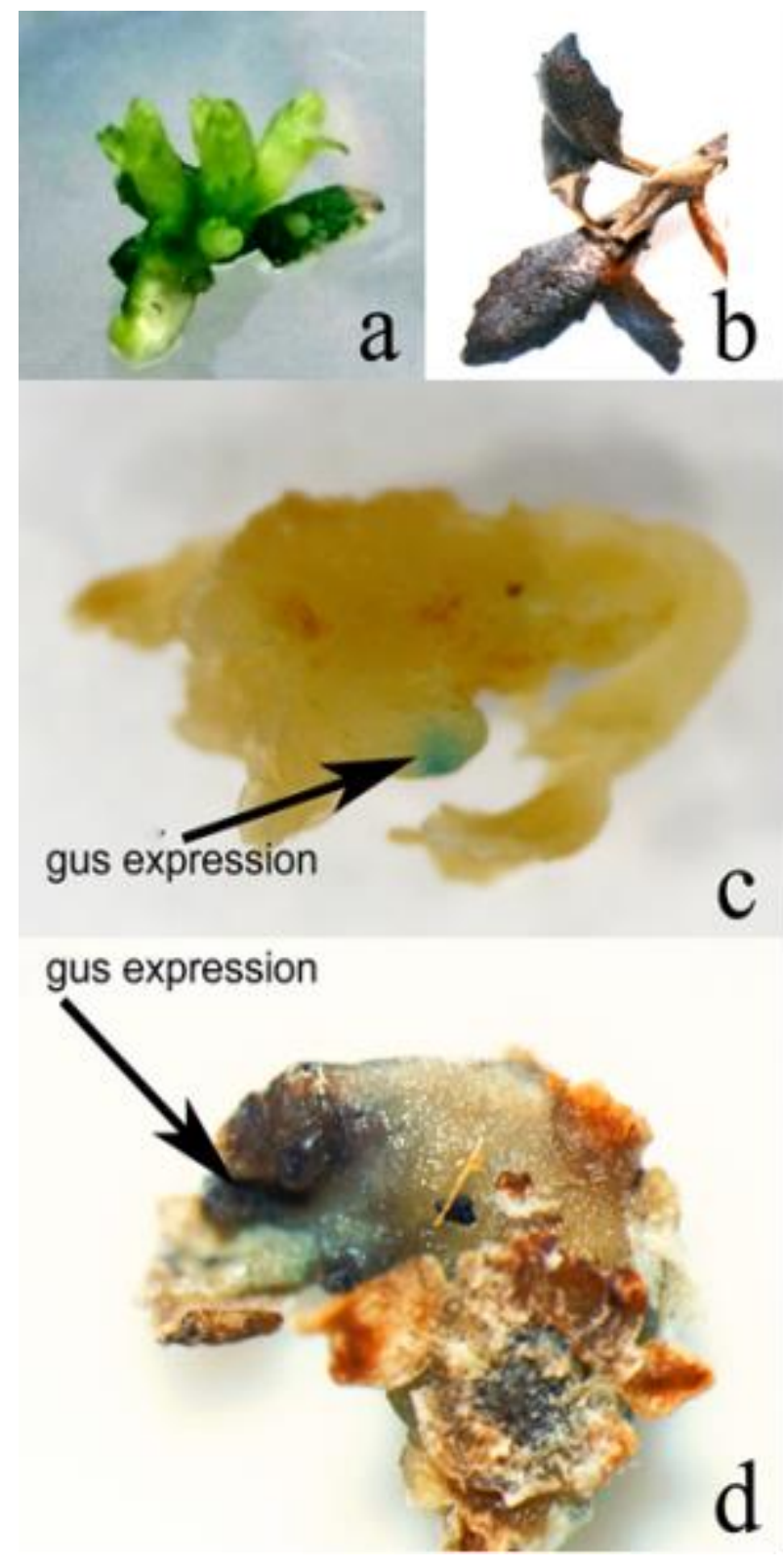

Figure 2 Agrobacterium mediated genetic transformation on L. aromatica (a) shoot proliferated using shoot tip explants (b) Histochemical Gus expression in transformed leaves (c) localised Gus expression in transformed cells and (d) Gus expression on callus cells

The methodology to generate transformation system is a key factor in transformation. Overall transformation efficiency as reported in this paper is very low, the establishment of efficient transformation system for rice paddy herb represents a significant achievement as it constitute first transformation report using this plant species. It is evident that this report will increase possibility of transgenic rice paddy herb making a definite contribution to the advancement of studies at molecular and biochemical levels. The results revealed that Limnophila is recalcitrant plant to Agrobacterium mediated genetic transfotmation. However, there is need to carry out further studies to see the mechanism of genetic transformation including behaviour of plant cell walls, their structural and chemical complexity in Agrobacterium mediated transformation. Genetic transformation is a powerful vehicle in studying gene function in plants and can be used for generation of new knowledge pathways involving the secondary metabolites production. This study may result in enhancement of production of important metabolites beneficial for living beings and may lead to development of important applications that will further enhance pharmacological significance of this important medicinal plant.

\section{Acknowlwdgement}

The authors acknowledge the Scientific Research Project Commission (BAP) of Karamanoglu Mehmetbey University for funding the project number 03-M-14. The part of research project was completed in Department of Agricultural Genetic Engineering, Faculty of Agricultural Sciences and Technologies, Niğde University, Turkey.

\section{References}

Bakhsh A, Anayol E, Ozcan SF. 2014. Comparison of transformation efficiency of five Agrobacterium tumefaciens strains in Nicotiana tabacum L. Emirates Journal of Food and Agriculture. 26:259-264.

Bhuiyan NI, Akter F, Chowdhury JU, Begum J. 2010. Chemical constituents of essential oils from aerial parts of Adenosma capitatum and Limnophila aromatica, Bangladesh Journal of Pharmacology. 5(1):13-16.

Brahmachari G. 2008. Limnophila (Scrophulariaceae): Chemical and Pharmaceutical Aspects. The Open Natural Product Journal. $1: 34-43$.

Bui ML, Grayer RJ, Veitch NC, Kite, GC, Tran H, Nguyen QCK. 2004. Uncommon 8- oxygenated flavonoids from Limnophila aromatica (Scrophulariaceae). Biochemical Systematics and Ecology. 32:943-947.

Cao S, Masilamany P, Li W, Pauls KP. 2014. Agrobacterium tumefaciens-mediated transformation of corn (Zea mays L.) multiple shoots. Biotechnology \& Biotechnological Equipments. 28:208-216.

Chhabra G, Chaudhary D, Sainger M, Jaiwal PK. 2011. Genetic transformation of Indian isolate of Lemna minor mediated by Agrobacterium tumefaciens and recovery of transgenic plants. Physiology and Molecular Biology of Plants. 17(2), 129-36. doi: 10.1007/s12298-011-0059-5.

Chi VV (1997-1998). Dictionary of Vietnamese Medicinal Animals and Mineral Substances. Health Publishing House. In Vietnamese.

Gorai D, Jash SK, Singh RK, Gangopadhyay, A. 2014. Chemical and Pharmacological Aspects of Limnophila aromatica (Scrophulariaceae): An Overview. AJPCT. 2(3): 348-356.

Gould JH, Magallanes-Cedeno M. 1998. Adaptation of cotton shoot apex culture to Agrobacterium-mediated transformation. Plant Molecular Biology Reporter. 16:1-10.

Hajian B, Piri K, Nazeri S, Ofoghi H. 2011. Agrobacteriummediated transfer of $\beta$-Glucoronidase gene ( $g u s A)$ to water mint (Mentha aquatica L.). Journal of Medicinal Plants Research. 5(5): 842-847.

Katzer G. 2014. Rice Paddy Herb (Limnophila aromatica [Lomk.] Merril). (http://gernot-katzers-spicepages.com/engl/ Limn_aro.html), [Accessed: 15 April 2016].

Khamwanı K, Akaracharanya A, Chareonpornwattana S, Choi YE, Nakamura T, Yamaguchi Y, Sano H, Shinmyo A. 2003. Genetic transformation of water spinach (Ipomea aquatica). Plant Biotechnology. 20:335-338. 
Kukongviriyapan U, Luangaram S, Kukongviriyapan V, Pakdeechote P. 2003. Alleviation of oxidative damage after Limnophila aromatica treatment in phenylhydrazineinduced anemic rats. Proceeding of the sixth JSPS-NRCT joint seminar : Recent advances in natural medicine research, December 2-4, 2003, Bangkok, Thailand.

Kumari U, Vishwakarma RK, Gupta N, Ruby, Shirgukar MV, Khan MB. 2015. Efficient shoot regenration and genetic transformation of Bacopa monnieri. Physiology and Molecular Biology of Plants. 21:261-267.

Lei J, Wang D, Shao L, Wei X, Huang L. 2012. Agrobacteriummediated transformation of cotton shoot apex with SNC1 gene and resistance to cotton Fusarium wilt in T1 generation. Cotton Genomics and Genetics 3:1-7.

Loganathan M, Maruthasalam S, Shiu YL, Lien WC, Hsu WH, Lei PF, Yu CW, Lin CH. 2010. Regeneration of soybean (Glycine $\max$ L. Merrill) through direct somatic embryogenesis from the immature embryonic shoot tip. In Vitro Cellular and Develeopmental Biology-Plant. 46:265-273.

Mahender A, Mallesham B, Srinivas K, Kumar GK, Venugopal Rao K, Rajesh Y, Zhang P, Sadanandam A. 2012. A rapid and efficient method for in vitro shoot organogenesis and production of transgenic Bacopa monnieri L. mediated by Agrobacterium tumefaciens. In Vitro Cellular and Develeopmental BiologyPlant. 48:153-159.

McCormick,S, Niedermeyer J, Fry J. Barnason A, Horsch R, Fraley R. 1986. Leaf disc transformation of cultivated tomato ( $\mathrm{L}$. sculentum) using Agrobacterium tumefaciens. Plant Cell Reports. 5:81-84.

Meerak J, Akaracharanya A, Leepipatpiboon N, Chadchawan S, Kaothien-Nakayama P, Shinmyo A, Sano H. 2006. Simultaneous Expression of Serine Acetyltransferase and Cysteine Synthase Results in Enhanced Sulfate Uptake and Increased Biomass in Ipomaea aquatica. Plant Biotechnology. 23:185-189.

Murashige T, Skoog F. 1962. A revised medium for rapid growth and bioassays with tobacco tissue cultures. Physiologia Plantarum. 15(3):473-497.

Nandakumar R, Chen L, Rogers SMD. 2005. AgrobacteriumMediated Transformation of the Wetland Monocot Typha latifolia L. (Broadleaf cattail). Plant Cell Reports, 23:744-750.
Nisha KK, Seetha K, Rajmohant K, Purushothama MG. 2003. Agrobacterium tumefaciens-mediated transformation of brahmi [Bacopa monniera (L.) wettst.], a popular medicinal herb of India. Current Science Association 85:85-89.

Ramesh M, Karthikeyan A, Vijayakumar K, Joe Virgin Largia M, Pandian SK. 2011. Agrobacterium- mediated transformation of pharmaceutically important Indian Medicinal herb Bacopa monnieri (L.). Journal of Medicinal Plants Research. 5:23162321.

Saha P, Datta K, Majumder S, Sarkar C, China SP, Sarkar SN, Sarkar D, Datta SK. 2014. Agrobacterium mediated genetic transformation of commercial jute cultivar Corchorus capsularis cv. JRC 321 using shoot tip explants. Plant Cell Tissue \& Organ Culture. 118:313-326.

Silva ALL, Oliveira Y, Costa JL, Mudry CS, Procopiuk M, Scheidt NG, Brondani EG (2011) Preliminary results for genetic transformation of shoot tip of Eucalyptus saligna Sm. Via Agrobacterium tumefaciens. Journal of Biotechnolgy and Biodiversity. 2:1-6

Sribusarakum A, Bunyapraphatsara N, Vajragupta O, Watanabe H. 2004. Antioxidant activity of Limnophila aromatica Merr. Thai Journal of Phytopharmacy. 11(2):11-17.

Wong SM, Sahidin N, Khalid N. 2010. Agrobacterium-Mediated Transformation of the Aquarium plant Cryptocoryne willisii with $g u s$ and $g f p$ Genes. Journal of Tropical Agriculture. 48(12):11-16.

Yadav S, Sharma P, Srivastava A, Desai P, Shrivastava N. 2014. Strain specific Agrobacterium mediated genetic transformation of Bacopa monnieri. Journal of Genetic Engineering and Biotechnology. 12:89-94.

Yamamoto YT, Rajbhandari N, Lin X, Bergmann BA, Nishimura Y, Stomp AM. 2001. Genetic Transformation Of Duckweed Lemna Gibba and Lemna Minor. In Vitro Cellular and Develeopmental Biology-Plant. 37:349-353.

Zhong H, Sticklen MB. 2000. Genetic engineering of corn: sustainability of shoot tip meristem in genetic transformation. In: Bajaj YPS, (ed.) Biotechnology in Agriculture and Forestry. Berlin, Heidelberg: Springer-Verlag. 